\title{
Translation as Style and Technique in the Hybrid Englishes of Raja Rao's Kanthapura and Eileen Chang's Lust, Caution
}

\section{Sreedhevi Iyer}

\section{Royal Melbourne Institute of Technology, Australia}

\begin{abstract}
The postcolonial writer and the translator of literary works possess similar literary challenges. Both are required to explicate unfamiliar elements from an original cultural source or text in a way that is comprehensible to a contemporary global audience. However, for the postcolonial writer this can amount to a certain didactic quality to the literary work, which is a devalued aesthetic within contemporary literary standards. As such, the writer incorporates translative elements in his creative process to get around the problem. To demonstrate this, I analyze and compare the works of two authors, Raja Rao and Eileen Chang. I argue that Rao's incorporation of the Kannada language into Kanthapura strategically resists prevailing standards of cultural explication, while Eileen Chang's initial draft of Lust, Caution, written in English as The Spyring, engages in overt cultural explication that fails to capture the nuances of its translated version. The intentional construct of linguistic and aesthetic permutations in both works can be characterized as an act of translation.
\end{abstract}

Keywords: Translation, Raja Rao, postcolonial, Kanthapura, Eileen Chang, Lust, Caution

$\mathbf{M}$ aria Tymoczko in her essay on translation and postcolonial literature sets out the parallels of translating as being metaphorical and analogous to the production of postcolonial literature. As a metaphor, she says, translation "invokes the sort of activity associated with the etymological meaning of the word: translation as the activity of carrying across" (Tymoczko, 19). Similarly, a postcolonial writer faces the task of transposing the complexity of his source culture to a receiving audience composed primarily of those from a different tradition, effectively rendering the writer's own heritage as a form of metatext that needs to be rewritten explicitly and implicitly in the process of literary creation (21). This process then calls to question Walter Benjamin's assertion:

Translation is a mode. In order to grasp it as such one must go back to the original for that contains the law for governing the translation: its translatability.

(Benjamin 152, my emphasis)

Writers of multiple cultures, most possibly residing within cosmopolitan centres foreign to them, and writing in the language of the colonizer with a multilingual sensibility, face issues of translatability in their 


\section{SARE, Vol. 56, Issue $1 \mid 2019$}

authorial choices almost on a constant basis. The creation of fiction in English, while seamlessly transmitting story elements across cultural and linguistic gaps, requires a similar "mode" of returning and assessing the "original" cultural elements and making decisions to enhance its "translatability". These are similar to the choices of a translator deciding on features of a source culture, such as objects, customs, historical allusions, foods, garments, weather, animals and such like, unfamiliar to the receiving audience, and adapting or modifying the text to achieve intelligibility.

The challenge here is for the author to achieve this without compromising on the literary quality of the work, especially in its empirical standards of narrative traditions coming from writing in the English language. This is especially problematic for the postcolonial writer, since unlike literature produced by and for a literary sphere, where cultural knowledge is presupposed and implicit, writing for an unfamiliar audience necessitates explication and foregrounding of cultural materials, which can amount to an instructional and didactic quality in the writing. The prevailing literary standards remain the product and legacy of the Romantics, which possessed, as per Terry Eagleton in Literary Theory, "a stress upon the sovereignty and autonomy of the imagination [and] its splendid remoteness from the merely prosaic" (Eagleton, 17) and which therefore values unique, original and individualistic enjoyment as the desirable aesthetic, from which contemporary ideas of the "symbol" and "aesthetic experience" has been inherited (Eagleton, 18). As such, elements of didactic and instructional literature in this contemporary literary climate has been devalued as being derivative - sometimes, as per Edgar Allan Poe in The Poetic Principle, almost to the point of heresy. There is, of course, also the choice of complete suppression of any distinctive cultural and linguistic qualities of the writer's original culture, but which also runs the danger of compromising the writer's cultural affiliations and the very motives for writing (Tymoczko 29). As such, in essence the current climate of literary standards places the postcolonial writer in a self-defeating circumstance, requiring engagement in explication, while simultaneously forbidding it. They find themselves in a paradoxical situation of being expected to not explain themselves but having to fulfil the demand of successfully achieving reader comprehensibility.

Consequently, it would seem inevitable that authorial decisions in the creative process of postcolonial writers to produce meaning in their work, would be couched in language, form and style that bring unique elements to the literary product that are outside the normative requirements of the English language. The purpose of this paper is to argue that such decisions and processes, to facilitate the comprehension and intelligibility of plural cultural and linguistic elements for the English reader's consumption, and thereby increasing access and appreciation of story to a fuller measure, is highly similar to the act of translation. 


\section{SARE, Vol. 56, Issue $1 \mid 2019$}

To this end, I examine texts from two authors of diverse backgrounds. The first is Kanthapura by Raja Rao, published in 1938. The title is the name of a South Indian village of the 1930s, which provides the setting for the action of the novel, depicting an idyllic and parochial life populated by villagers who are content in their traditional lifestyle. The pastoral image is shattered by highly political events as the Indian Independence movement finds its way into the village, complete with caste reforms and satyagraha. The novel is a long, oral tale narrated by an old Brahmin grandmother named Achakka, and contains an amalgamation of the villagers' myth-ridden beliefs, along with the reformer Moorthy's pragmatic, Gandhian principles.

Raja Rao himself, considered a philosopher-novelist, was born in Mysore, Karnataka, and lived and wrote in France, at the University of Montpellier, and later the Sorbonne. He wrote in both English and French, before returning to India in 1939 to join the nationalist movement. He later moved to the United States, and was Professor of Philosophy at the University of Texas, Austin. He passed away in 2006 at the age of 97.

The second book, Lust, Caution, is by Eileen Chang, or Zhang Ailing, a Chinese author who lived in Shanghai before moving to the US where she spent the rest of her life. Chang is considered one of the most prominent Chinese writers of the twentieth century, and has been exhorted as deserving of the Nobel Prize for Literature if not for political factors between China and the West. Born of an Anglophone family in Shanghai, Chang attended an English medium school and studied literature at the University of Hong Kong before returning to Shanghai due to the Sino-Japanese War. She subsequently moved again to Hong Kong in 1952, and then the United States in 1955.

As a bilingual writer, Chang has self-translated several of her works, playing with both Chinese and English literary conventions. It is believed that the idea for Lust, Caution germinated after her departure from China in the early 50s, although the story in Chinese was not published until 1979. According to her observers and critics, this is a story Chang returned to for nearly thirty years. It was subsequently translated into English by Julia Lovell in 2007, a reputed, prize-winning translator. During the media blitz surrounding the release of the film version of Lust, Caution ${ }_{2}$ directed by Ang Lee, the Hong Kong magazine "Muse" published the typewritten manuscript of an initial draft of the story by Chang, which was in English.

For the purposes of this paper, I choose to focus on comparing the English translation of Lust, Caution by Julie Lovell to an earlier English draft that Chang herself had attempted, nearly thirty years earlier. The comparison of the two versions reveals differences in the selection of explication of non-Western elements - an element that is also crucial and intrinsic to the translation process (Tymoczko 35).

Raja Rao, too, employs an inventive style in the telling of the Kanthapura tale, derived from oral legends. I examine this aspect first. I also explore the notion that his language contains an unapologetic use of foreign 


\section{SARE, Vol. 56, Issue $1 \mid 2019$}

vocabulary, expressions and idioms, with occasional explanations but many times, none. Much of the language could be seen as having been transliterated from Kannada, injecting the English language with a particular flavour of the region. Rao is highly aware of his inventiveness, as can be seen in the exploration of his assertive foreword, where he champions, decades before Rushdie, a literary creativity in English that enmeshes rather than excludes Indian mother tongue influences. Kanthapura possesses the aura of oral folklore, an element A.K. Ramanujan insists is an essential element to understanding Indian culture (513).

In this article, I argue that the differences in Eileen Chang's two versions of Lust, Caution, as well as Raja Rao's inventive English in Kanthapura point to the same issues a translator would have, that of facilitating access from incomprehension to intelligibility. As such, I argue that translation has occurred in both authors' processes, rendering their narratives in hybrid Englishes atypical of contemporary narrative traditions.

\section{Raja Rao's Kanthapura}

Raja Rao negotiates Kannada and English in Kanthapura — two languages that, according to Vinay Dharwadker when discussing A.K. Ramanujan's approach to translation, resist Walter Benjamin's value of "transparency" due to inherent differences in the languages' characteristics:

English and Kannada, for example, use two rather different finite sets of means - sounds, scripts, alphabets, lexicons, grammars, syntactic rules, stylistic conventions, formal and generic principles and so forth - to generate their respective infinite bodies of discourse, including poetry. Consequently, a modern English translation of a premodern Dravidian-language poem, no matter how skilful, can never be 'transparent' the way Walter Benjamin, for instance, idealistically and formalistically thought it could be. Ramanujan felt that the systemic differences between two languages ensure that Benjamin's norm of a 'literal rendering of the syntax' of one is impossible in the other, and that a compensatory focus on individual words in such a situation (at the expense of structure or design) conflicts with the translator's obligations to render the poem's inner and outer forms faithfully. (Dharwadker, 118)

Rao, as though in agreement with Ramanujan, employs resistant strategies in Kanthapura. He embeds the Kannada language in various ways in the narrative, at times eschewing explanation. This, as we shall see, renders the text not transparent but opaque. The text is not a "faithful" or "literal rendering" of Kannada influences in English, but is foreign enough in character as to seem invented. This implicitly shifts the text away from standards 


\section{SARE, Vol. 56, Issue $1 \mid 2019$}

of the English language with intentional grammatical anomalies, transliterated syntax, idiomatic expressions and use of Kannada vocabulary. However, this shift in no way alters the text's storytelling aspect - there are no interruptions to the narrative for the sake of explication.

Rao also intentionally applies the form of the oral folk tale to the narrative of Kanthapura. He employs the Indian folk tradition of the sthalapurana, or the legend of the local temple. In doing so, he recreates English within this tradition of "legendary history", and again transforms the language into a hybrid creature.

Rao's celebrated foreword to Kanthapura sheds light on the author's intentions in rendering the English language pliable to his purposes. Hailed by R. Parthasarathy as "revolutionary in its declaration of independence from English literature" (157), Rao asserts:

We cannot write like the English. We should not. We cannot write only as Indians. We have grown to look at the large world as part of us (Rao ii, my emphasis).

Here Rao resists trying to assimilate into English narrative traditions, while also acknowledging the influence of the larger, foreign world on the Indian literary psyche, and that therefore, the actual English that "should" be used, the language that is most suitable and true for the postcolonial writer, is one that is not either English or Indian but both. To that effect, Rao is also highly aware of the demands placed on him, when he admits "one has to convey in a language not one's own, the spirit that is one's own" (Rao iii) and the challenges faced when needing "to convey the various shades and omissions of a certain thought-movement that looks maltreated in an alien language" (Rao iii). This chapter explores these "shades and omissions" in an attempt to discover the author's processes and its consequences on the language.

\section{Oral narratives: Kanthapura as sthalapurana}

Rao admits in his foreword to exploiting the style of the Indian oral epics of the Mahabharatha and the Ramayana, citing that as "the ordinary style of our storytelling". He highlights his stylistic inventiveness as being a consequence of retaining the oral flavour of the Hindu puranas, or scriptures, which lend themselves to a different set of linguistic rules to achieve a similar oral effect: 


\section{SARE, Vol. 56, Issue $1 \mid 2019$}

The tempo of Indian life must be infused into our English expression, even as the tempo of American or Irish life has gone into the making of theirs. We, in India, think quickly, we talk quickly, and when we move we move quickly... And our paths are paths interminable...We have neither punctuation nor the treacherous 'ats' and 'ons' to bother us - we tell one interminable tale. Episode follows episode, and when our thoughts stop our breath stops, and we move on to another thought. (Rao ii)

As such, Achakka's narration is also episodic, even as she tells "one interminable tale", which Rao envisions would have occurred over the course of a single evening (Rao ii). Rao establishes the oral quality of the tale right from the outset, employing long sentences that seem to run onto one another, as the actual sthalapurana, or temple legend of the novel is introduced:

Kenchamma came from heaven - it was the sage Tripura who had made penances to bring her down - and she waged such a battle and she fought so many a fight that the blood soaked and soaked into the earth and that is why the Kenchamma hill is all red, if not, tell me, sister, why should it be red only from the Tippur stream upward, for a foot down on the other side of the stream you have mud, bleak and brown, but never red. (Rao 3)

The "thought-movement" of the sentence shifts constantly from one to another, from the reason why the goddess comes to earth, to an opinion proving the tale's veracity, while addressing the listener in between. The gossipy tone, paratactical structure and loose sentence construction give a sense of immediacy, and also a sense of listening to speech rather than reading a text. The "hurried and breathless tempo" that M.K. Naik associates with Rao's style corresponds with Rao's attempt to follow “the tempo of Indian life", of thoughts stopping only when breath also stops (60).

Similarly, in keeping with the idea of "hearing" rather than "reading" the story, Rao favours a certain grammatical looseness, averting a standardized use of English. He asserts this in the opening passage of the novel itself:

Our village - I don't think you have ever heard about it - Kanthapura is its name, and it is in the province of Kara. High on the Ghats is it, high up the steep mountains that face the cool 


\section{SARE, Vol. 56, Issue $1 \mid 2019$}

Arabian seas, up the Malabar coasts is it, up Mangalore and Puttur and many a centre of cardamom and coffee, rice and sugarcane. (Rao 1 , his emphasis)

The inversion of "it is" to "is it" indicates a transliterative element, although it is so minor as to give the impression of incorrect grammar.

Similar alterations in structure occur in "I am telling you what is the law" (Rao 14) and "But hardly had he finished..., and was just about to light the camphor..., than the Sankur police jemadar is there" (Rao 12). The first sentence seems to go against the subject verb order, while the latter dispenses with the requirement of "when", with a sense of control having been passed from the word "hardly" instead.

The grammar deviations continue in the form of mixed verb tenses, shifting prepositions and use of alternative resumptive modifiers. There are several sentences that contradict tenses, as the examples below show:

We gave a sari..., and the goddess never touched those that are to live - as foretold ones, they would have died... anyway. (2, my emphasis)

After that he would take his coconut and money offerings and hurry down to Pandit Venkateshia's house...Bhatta is the First Brahmin. He would be there before it is hardly eleven... and he would begin... Never has anything better been seen. And it was so pleasant... (21, my emphasis)

The...Committee had written to Moorthy to go and see them. And when he had gone to see them they had given him books.... (17, my emphasis)

Together, the examples illustrate an inconsistent time-frame, and a lack of a consistent referent past tense event. The literary device of a non-standardized format, sprinkled across the text, supports Achakka's rambling style, in line with the conceit of the story being orally told, and thereby requiring an increased consciousness of interpretation on the reader's part.

The shifting prepositions underscore this further. The samples below use alternative prepositions to that employed in normative English:

Get a kick on the stomach (139)

Walk the holy fire on the annual fair (2)

Put glass panes to the windows (3) 


\section{SARE, Vol. 56, Issue 1 | 2019}

The 'on's would normally be replaced by 'in's, and glass panes are usually put 'up' without 'to's, just as in "believe in such a crow-and-sparrow story" (15) and "up the Malabar coast is it, up Mangalore and Puttur and many a centre" (1), the deviation is from where one believes a story without "in," and in locating a place up somewhere without "from."

The reader further needs to employ aural strategies of "listening" when faced with resumptive modifiers that are placed in sentences that would normally be frowned upon in assessing native English style, as in:

The Tiger, his words were law (6)

He goes, Moorthy, from house to house (9)

There were other stories, he told us, Jayaramachar (12)

Braj Kachru in The Indianization of English argues the different rhythms of English as opposed to South Asian languages, where the latter is syllable-timed, rendering its language patterns different to English's stresstimed rhythms (32). Rao's minor deviations from standard English grammar (as opposed to more deliberate syntactic, lexical creativity, as discussed later), seem to accumulatively reshape and reformulate the colonial language's native rhythms into the local Indian vernacular, by bending the rules of the colonial language. The non-deferential attitude towards "the 'at's and 'on's that bother us" which disrupt the all important rhythms and intonations of the sense of continuous, unbroken narration, the "interminable tale," results in a new, hybrid language that, despite being English, still sounds Indian.

The different rhythms in South Asian languages and English, according to Kachru, hampered the intelligibility of Indian English to native English speakers (32). However, Rao circumvents the intelligibility issue by employing large amounts of paratactical structure to his sentences, as in this passage:

So Bade Khan went straight to the Skeffington Coffee Estate and he said, "Your Excellency, a house to live in?" And Mr. Skeffington turned to his butler and said, "Give him a hut", and the butler went to the maistri's quarters and opened a tin shed and Bade Khan went in and looked at the plastered floor and the barred windows and the well nearby, and he said, "This will do," and going this way and that, he chose a Pariah woman among the lonely ones, and she brought along her clay pots and her mats and her brooms, and he gave her a very warmful bed. (15) 


\section{SARE, Vol. 56, Issue $1 \mid 2019$}

Rao's usage of archaic terms such as "warmful" adds to the ancient fable-like quality of the narrative, however the coordinate clauses in the passage, linked often with "and", prove to be a dominant feature in the narrative. Rajend Mesthrie in English in Language Shift asserts the use of parataxis in Indian languages to be significantly higher than hypotaxis, and that consequently contemporary Indian English speech employs similar sentence structures (102). Rao seems to have understood this much earlier, and adapts the "sing-song" rhythmic quality of Kannada through the use of paratactic syntax, and thereby showcasing an Indian English at a very early, pre-Independence period. And as the above passage illustrates, the choice of parataxis allows this adaptation, without losing intelligibility or comprehension of the narrative.

In essence, Raja Rao reworks features of oral narratives into his fiction to achieve a similar effect on the reader. The application of this artifice, done with the intent of retaining a cultural context in the narrative, has resulted in creative choices that displace and distort normative rules of the English language, allowing for an alternative, almost pidgin language, which is nonetheless completely intact in storytelling merit.

\section{Creation of dialect: linguistic interferences in Kanthapura}

R. Parthasarathy, Raja Rao's editor, observes in a tribute in The Hindu that "in Kanthapura English is thick with the agglutinants of Kannada." He observes Rao's experimental style as English that has been "ritually deAnglicized." This ritual has been meticulously conducted through a linguistic reworking which foregrounds agglutinative Kannada elements in the building blocks of language, through coinage of idiomatic expressions, lexical and syntactical creativity, and lexical based loan shifts. Braj Kachru points to the result of such linguistic creativity, saying that the "interaction of an 'alien' language in a 'non-English' context results in the newness in the new varieties, styles, and registers of English" (The New Englishes and Old Models 32). Such interaction has produced a hybridized linguistic product, as a result of what Kachru says is a "deviation", an exercise that "involve[s] differences from the norm, and may be necessary in the cultural context in which a language functions" (Indian English 284).

One of these necessities that Rao engages with is the use of Indian language equivalents and approximations in the language, rendering it highly idiomatic. M.K. Naik argues that these idioms are "the author's own coinages...these are completely in harmony with the actual translations made from Kannada" (74). The harmonious replacements also do not obstruct easy comprehension. For example, similes such as "honest as an elephant" (Rao 9), "as good as kitchen ashes" (27), despite being invented using non-Western reference points, do not obscure meaning. Elephants possess character reputations in the West as much as anywhere else, and "kitchen ashes" clearly denote the word "good" to be ironic, and therefore the expression to mean "useless." 


\section{SARE, Vol. 56, Issue $1 \mid 2019$}

Similarly, Rao conveys specific cultural information by weaving it into coined expressions. As such, a phrase like "let the castes exist, let the separate-eating exist" (Rao 27) joins the ritual of eating separately to the requirements of the Indian caste system, however a phrase like "she will "come home soon" (22) calls for more than one interpretation. In its context, the reader could take it to mean either "come of age" or to "enter adolescence." The use of quotation marks, also used to frame the phrase "'Don't-touch-the-Government' campaign" (60) underscores the coinages as artificially fashioned expressions, signifying to a universal reader the text's non-English influences in its linguistic usage.

It is interesting to note that instead of dispensing with British idioms, Rao does use them, opting for clichés that sound archaic to the contemporary reader, such as "so much the better" and "to tell you the truth" (5). Further renderings of such expressions seem to be analogous to English expressions, such as "a-crow-and-sparrow story," (15) "every squirrel has his day" (77) and "not a mosquito moved" (100). These seem to suggest not a literal translation occurring, but an application of a "mode" of translation - of couching indigenous meaning in the idiomatic code of the colonial language, and thereby making it adhere to neither set of usage standards.

Rao also modifies grammatical usage, so that the rendering of the Harikatha, the traditional storytelling form that the village enjoys, is described using both "do" and "make", as in "but the Harikatha he did" (10) and "never has anyone made a grander Harikatha" (8), which suggests their usage in terms of the accepted semantic shifts of the same word in Kannada, as opposed to the more rigid rules of their usage in English. The same goes for the application of the word "outcast" as a transitive verb, as in "he will outcast every Brahmin who has touched a Pariah" (27) and "have him outcasted" (30), which also suggests an application of Dravidian rules of grammar, where the term, possibly in high use in discussion of Indian social norms, would be often applied as a transitive verb.

Rao also employs such culture-specific idioms in modifiers in nominal groups that fix the identity of the characters of the novel, which effectively illustrate the highly complex social gradation of village society. Character names are always referred to in relation to a social aspect, thereby locating them in the social matrix of Indian rural life. As such, characters are addressed as "Coffee-Planter Venkatanarayana", "Postmaster Suryanarayana" and "Carpenter Kenchayya" denote occupation. "Corner-house Moorthy" and "cardamom-field Ramachandra", "Kuppur Suryanarayana" suggest geographical proximity. "Nose-scratching Nanjamma" has to do with her habit, while "Pariah Rachanna" clearly exposes caste. The mode of reference mimics the particular form of social address used in South Indian communities. It must be noted here that such form of address is not articulated in English by South Indians, but in the local vernacular. As such, Rao's stylistic deviation here in using this form of address in English is another example of transliterative elements within the text. 


\section{SARE, Vol. 56, Issue $1 \mid 2019$}

The alteration of modes of address also affects the novel's syntax, with an inconsistency yet again. Rao uses three different ways of referring to the reformer group of the village, who take their leadership from Mahatma Gandhi. They are alternatively called "Gandhi's men" (11), "a Gandhi's man" (34) and "a Gandhist" (19). While all mean the same, each choice seems to be an experimental way of rendering the epithet, and the difference in the morphological features here points to patterns of reference external to the measures of the English language.

Rao does not restrict the use of Kannada to the novel's syntactic and lexical features - he also applies it to semantics, resulting in shifts of cultural meaning. For example, Narsamma addresses Waterfall Venkamma as "sister" when they meet at the river, a day after Venkamma had viciously insulted her:

And when Narsamma saw her at the river the next day, Venkamma was as jolly as ever and she said she had a bad tongue and that one day she would ask Carpenter Kenchayya to saw it out, and Narsamma said, "Oh, it does not matter, sister", and they all talked together happily and they came back home, their baskets on their heads, content. (Rao 57)

Firstly, the phrase "bad tongue" itself is a calque, a literal translation from Kannada. The kinship term "sister" here however is not intended to possess its literal meaning of biological relations. Kachru in The Indianization of English clarifies this:

In English, brother, sister, or brother-in-law all belong to the lexical set of kinship terms. In...[non-native English] extra semantic features are assigned and their range of functions in other lexical sets widened. (46)

As such, according to Kachru, the term could be used as a particular mode of address, as well as to attach further meanings of affection, regard or abuse. Narsamma, therefore, is applying the term as a measure of politeness, indicating an acceptance of the apology and a restatement of convivial bonds.

The calques are also in semantic extensions, for example when Venkamma makes the trip to go see Narsamma and give her a piece of her mind:

and she walked fast, and when she came to Moorthy's house she planted herself straight before his mother and cried, "Narsamma, I have come to ask you something." (56, my emphasis)

Instead of the phrase "stand in front of", Rao again follows a literal translation from Kannada, performing a loan-shift in making Venkamma stand "straight before" Narsamma. 


\section{SARE, Vol. 56, Issue $1 \mid 2019$}

Such cultural signifiers ring out to the Indian bilingual reader, however, again, the acrobatics with English is not opaque to the point of non-comprehension to a monolingual reader.

\section{Rao: A Conclusion}

Ramanujan, in clarifying his stance on translation, posits:

The translator is expected to render textual meanings and qualities 'literally', to successfully transpose the syntax, design, structure or form of the original from one language to another, and to achieve a communicative intersection between the two sets of languages and discourses. At the same time, the translation has to attempt to strike a balance between the interests of the original author and those of the translator...to construct parallels between the two cultures and the two histories or traditions that it brings together (qtd in Dharwadker, 115, my emphasis)

The interference with the normative usage of English in Kanthapura at its lexical, syntactic and structural level occurs with sufficient degree and frequency to form the “communicative intersection.” However, it is Rao's balancing act, his vested interest as the original author, that is more intriguing. As if in additional emphasis to Rao's foreword, G.J.V. Prasad argues that "many Indian English writers create the language in which they write" (54), an aspect that goes beyond mere flavouring of the English language with an Indian tilt. Mulk Raj Anand hints that Rao had such interests, which are beyond merely showcasing a culture "for sale to the jaded reading public, in a manner which may be easy...to swallow" (39). It seems to refer back to the issue of explication to a monolingual, culturally unfamiliar audience, and adopting an unapologetic stance towards it.

Instead, in adopting and incorporating vernacular rules and styles into the text, to form what Kachru terms "author-oriented" collocations (76), Rao seems to have made the same authorial choices that a translator would have. There are literal translations, but there are also influenced idioms and expressions that, like a work of translation, "do not go against the grain of the English language” (Mukerjhee 174).

In essence, then, Raj Rao, in constructing his own patriotic, nationalistic, pre-Independence sthalapurana in the language of those he seeks freedom from, consequently conjures a linguistically hybrid intersection that occupies a space in-between English and Kannada. With this particular postcolonial stance, Rao, unlike Chang, perhaps unconsciously, places himself in the role of Kailash Baral's "folklorist translator" — in that he is implicated in both acts of creation of folk text as well as translating it into the target language (Baral 29). As such, in line with Prasad's observation that 'the texts [Indian English writers] create are 'translated', the very act of 


\section{SARE, Vol. 56, Issue 1 | 2019}

their writing being one of translation" (41), one could say that Rao's extensive, comprehensive choices of applying non-English elements within his text in producing Kanthapura, and the resultant enriched language, qualifies his process as one of translation.

\section{Eileen Chang's Lust, Caution}

Set during the Sino-Japanese War, the story of Lust, Caution primarily concerns the protagonist Jiazhi, a member of the Chungking spy network, and her attempt to facilitate the murder of a Chinese collaborator, Mr Yi, by becoming his mistress and performing the role of informant. She asks him to buy her a diamond ring as part of a ploy to capture and murder him, but believing him to really love her, she saves him at the very last minute by warning him. Having escaped, Mr Yi orders the capture of everyone in the network, and has them put to death, including Jiazhi.

In the earlier draft, "The Spyring”, the names of Mr Yi and Jiazhi's precursors are Mr Tai and Shahlu, respectively.

I attempt to compare the initial English draft of Lust, Caution, in Chang's own words, with the translated version by Julie Lovell. I approach the text and translation from the subject position of the transnational audience, especially as the story has been made into a movie of wide circulation across the global mediasphere. As such, for the purposes of this essay, I assume Lovell's English translation of Eileen Chang's Chinese version of Lust Caution to be a faithful rendering of the Chinese version of the story. I attempt this comparison to examine the differences in degrees of cultural explication, and how such differences illuminate the author's consciousness and assumption of a familiar audience as opposed to a foreign one, which informs the variables in the two texts.

However, it should also be noted in this analysis that the English version is an early draft, which has been substantially revised, as Julia Lovell's translation shows. A larger, more detailed backstory for the protagonist's motivations has been mapped out, increasing reader sympathy, while a significant passage where she attempts her escape through the streets, and assaulting a man with her ring, causing him grievous harm, has been omitted. As such, I focus my analysis on the aspects that are present in the earlier English draft and have been retained right up to Lovell's translation.

\section{Title}

The title Lust, Caution, is a translation of Se Jie, a Chinese title that contains the visual pun of Se to mean both sexuality and vision (to see), and Jie, meaning both warfare and forbiddance. The arrangement of the Chinese 


\section{SARE, Vol. 56, Issue $1 \mid 2019$}

characters visually construes mirror images, denoting the parallel aspects of both concepts, an element that Lovell attempts to replicate in the English title and the use of the comma. The title in that sense illuminates the themes of the story, of forbidden love during wartime, and of sexuality as a weapon.

However, Chang's earlier English version contains two different title suggestions - the typewritten title is a Chinese expression, "Ch'ing K'e Ch'ing K'e," with another title handwritten on top, “The Spyring”. Unlike the elegant visual pun of Se Jie, the 'Ch'ing K'ei' expression is contextualised within the text, as an urging by Mrs Tai:

You're getting stuck-up these days...Ought to be punished. Ch'ing k'e, ch'ing k'e! Stand us dinner, stand us dinner!"... It was a game that they never tired of playing, demanding to be stood dinner all round at the least excuse. (3)

Lovell's version in contrast contains a mild assertion, where Yi Taitai exclaims "you're going to treat us all to dinner tonight!" (Chang 8), without supplementary information. The title is expressly transliterated in the passage as "stand us dinner," a phrase that is grammatically incorrect but possesses a ring of foreignness to it.

However, the second title suggestion, "The Spyring," contains within it a pun, a device that eventually retains itself in the final name, Se Jie. Referring to both the ring of spies that the protagonist Shahlu belongs to, as well as the actual jewellery that Shahlu insists on purchasing as a front to lure Mr Tai on to enemy territory, "The Spyring" contains a dual meaning in English that is successfully supported in the text of the draft. The very first paragraph highlights that "diamond rings flashed" on the hands of the ladies Shahlu socialises with, and later, Mr Tai's willingness to purchase an expensive ring for Shahlu allows her to "see" him more clearly, as someone who truly does love her. She tells herself "there must be flaws in the diamond" (12) given its size, and her realisation happens in an environment of "fluorescent light tubes" that shine up at her "like footlights" (12) so that when she has urged him to run away and flees from the shop herself, the fact that "it was still light outside" surprises her (14). The altered lighting has influenced her vision of Mr Tai, and her own feelings towards him, resulting in an act of betrayal by warning him and allowing his escape. Shahlu fails her ring of spies surrounding the shop, waiting to strike their target, because of a momentary realisation of a deeper truth due to the gift of the diamond ring. In essence, the "spyring" has been broken.

It is interesting here to note that Shahlu's altered vision eventually becomes incorporated into the final

title, Se Jie, while the ring motif, dropped from the title of the initial draft, becomes more apparent in the Lovell text. The section in the jewellery shop is more detailed and slowed down, with the jeweller, and aspects of the diamond ring gaining more prominence. The alteration indicates an authorial awareness of audience, in deciding 


\section{SARE, Vol. 56, Issue $1 \mid 2019$}

the incorporation and exclusion of literary elements. While "Ch'ing K'e" had to be expressly transliterated in repetition, making it obvious to the reader as to its foreign origins and meaning, "The Spyring" employs puns, a legitimate device common in Chinese due to the visual elements of the language, but which is considered a lower form of literary style by contemporary standards. Unlike Rao, the consideration of a foreign, non-Chinese audience, has resulted in a text that attempts to explain itself, as opposed to the later Chinese version, which freely employs the devices in view of its culturally specific audience.

\section{Cultural explication}

This awareness of a non-familiar audience is something that permeates the draft of "The Spyring", which, in contrast to Lovell's translation, exposes the difficulties of the bilingual author's decision-making process in creating fiction in English. As Chang was writing in the United States, "The Spyring" fits into the mould of what, according to Jessica Li, Chang was attempting with her other stories around the same time, as "experiment(s) in using English to write a culturally Chinese story for an English reading public" (101). One of the elements that Li notes is that "When (Chang) writes for an English-speaking audience, she consciously elaborates upon Chinese cultural elements in order to enable these readers to understand the cultural context" (101). This is especially evident in "The Spyring”, which contains express explication of elements that Lovell's translation merely assumes or embeds within the text.

For example, Yi Taitai in Lust, Caution is described as possessing a figure that "still seemed to bell outward from her neck" (Chang 4) despite her age and weight. The visual element is portrayed as a positive aspect of her beauty, suggesting a well-preserved physique. The subtle, passing description obtains larger proportions in "The Spyring," where:

It has been said in the ancient classics that a woman's ideal posture is "Like a bell when seated; like a pine tree when standing; like a wind when walking; like a bow when sleeping. Mrs. Tai, the hostess, was as firmly set on her chair as a bell even if she didn’t have her cloak on." (1)

What took up a part of a sentence in Lust, Caution takes up nearly a paragraph in "The Spyring," due to the explication of the meaning of seeming like a bell while seated in "the ancient classics" of Chinese literature. Mrs Tai's "bellness" gains larger cultural proportions and importance in the English version, although it serves no other literary purpose other than to inform the reader of cultural context. The same effect of elegance in physicality comes through in both versions, with more economy in Lust, Caution, due to an assumption of an audience that would already understand the extra connotations of "bell." 


\section{SARE, Vol. 56, Issue $1 \mid 2019$}

Similarly, there are specific explications of cultural contexts and linguistic elements in "The Spyring" that are either missing or barely mentioned in Lust, Caution, suggesting a change of audience, reflected in the cultural assumptions made within the text. For example, when Mr Tai enters the mahjong room, Mrs Tai in "The Spyring" makes a fuss that is absent in Lust, Caution:

A book is $s h u$ and "to lose" is also pronounced shu. "No wonder I'm losing, with people standing behind me with shu in their hands!" (4)

By explaining "shu", the narrator dilutes the impact of Mrs Tai's dialogue, although the reader understands the pun. The effect is somewhat similar to a narrator stepping outside the narrative to read out from a dictionary or encyclopaedia, something that recurs later in the story, when Shahlu attempts to sweet talk Mr Tai into going to the jewellery store:

She fully expected Tai to recognize it as what was commonly known as kwang mi-t'ang, administering the witching potion. (11)

Though narrated from Shahlu's point of view, with close psychic distance, qualifying "kwang mi-t'ang" as a "commonly known" expression seems anachronistically included for the benefit of those to whom such a phrase is not known at all, and again exposes a narrator attempting contextualisation. It is interesting to note that both expressions above find no place in Lust, Caution.

At the times that such expressions are present, they are comparatively far more muted and subtle. For example, when Mrs. Sun urges Mr Tai to play mahjong in "The Spyring", she says, "It's a sin to refuse when it's san ch'ueh yih, three lacking one" (6). The dictionary translation, "three lacking one" and the fact that it is "sinful", is replaced merely by the fact that "mahjong's no fun with only three." (8) It's interesting to note that the degree of courtesy and rudeness differs in each version. The breaking of convention seems harsher in "The Spyring," and a lesser transgression in Lust, Caution, due to an implicit understanding of context.

The different degrees of explication extend to place descriptions as well, and in this aspect "The Spyring" employs far more evocative language, painting a loving visual of the café Shahlu goes to contact her spy comrades:

The narrow passage where she went to telephone looked and smelled like a crowded train with its lamplit chocolate brown walls, an icebox chug-chugging away in the vicinity and rows of the waiters' clothes hanging down from high hooks overhead, white smocks and long gowns with soiled cloth linings. Shahlu had the faintly excited and vacant feeling of a person going on a journey. (6) 


\section{SARE, Vol. 56, Issue $1 \mid 2019$}

The travel metaphor is eliminated in Lust, Caution:

Its large interior was lit by wall lamps with pleated apricot silk shades, its floor populated by small round tables covered in cloths of fine white linen jacquard - an old-fashioned, middlebrow kind of establishment. (Chang 9)

Here, the atmospheric language and didactic ones have switched places. The Chinese version makes compact mention of the place, trusting that brief descriptions of "old-fashioned" and "middle-brow" is sufficient for the reader, presuming enough knowledge of place and time to conjure an accurate image of the setting. Conversely, the time period is more meticulously set out in "Spyring" with the presence of "lamplit" walls, chugging iceboxes and waiters' smocks and gowns. The sensory descriptions allow access to a reader unfamiliar with Hong Kong's old-fashioned establishments, a phenomenon insider readers would take for granted.

The most interesting differences, though, are the ones that illuminate the theme of the story, with its tragic elements. Towards the end of Lust, Caution, as Mr Yi ruminates on having ordered the death of Jiazhi:

He could have kept her on. He had heard or read somewhere that all spies are brothers; that they can feel a loyalty to one another stronger than the causes that divide them...But real men have to be ruthless. She wouldn't have loved him if he'd been the sentimental type. (Chang 34)

The mention of the saying germinates in "The Spyring," and although the tragedy of the relationship dynamics is maintained, the saying is used for an opposite sentiment:

Since the war began there had been this saying, T'eh wu pu fung chia, special agents are all one family, because they could switch sides with ease. He couldn't have a woman like that near him. He had no choice but to kill her, being the kind of man that she had been in love with. "No venom, no hero," as the ancient saying went. (18)

The specificity of the saying is watered down in Lust, Caution, however unlike "The Spyring," Mr Yi uses it to wonder if he could have left her alive, knowing her loyalty was fickle due to her love for him. The resultant justification, echoed in both versions and unsurprisingly explicated in "the ancient saying" of "No venom, no hero," gains a higher tragic note in Lust, Caution - he could have left her alive but decides not to because he wanted to remain the kind of man she loved, rather than in addition to. The linguistic complexity in Lust, Caution elevates the tragedy to more acute levels, since the author is not saddled with considering a foreign readership and their cultural comprehension. 


\section{SARE, Vol. 56, Issue 1 | 2019}

Given the amount of linguistic and cultural explication in "The Spyring," however, it is surprising to note a key Chinese-based phrase in Lust, Caution, that effectively permeates the subtext of the whole story, absent from the initial draft. Mr Tai's twisted sense of satisfaction at having murdered a beautiful woman who loved him, is retained in both versions. However, while he is summarily executed in "The Spyring," in Lust, Caution he only considers his bleak future while privately gloating at his triumph over his lover:

But now that he had enjoyed the love of a beautiful woman, he could die happy - without regret.... And now he possessed her utterly, primitively - as a hunter does his quarry, a tiger his

kill. Alive, her body belonged to him; dead, she was his ghost. (Chang 35)

In speaking of his power over her, in life and in death, Mr Yi evokes a depiction of the Chinese saying of “the tiger's ghost", or wei hu dzuo chung, which in literal translation means "one killed by the tiger, whose ghost willingly works for him to lure others". The phrase, according to Ang Lee, was also popular during the SinoJapanese War, where the story is set, to refer to the Chinese who collaborated with the Japanese during the War, and is also used to mean "prostitute" (35). Yi equates Jiazhi to the ghost, and him to the tiger that killed her, although, by virtue of being a collaborator that the Chungking spies wanted to dispose of, Yi was a "ghost" himself, or rather, a "prostitute," as well.

The phrase and its irony is not present in "The Spyring," although Mr Tai is actually reported to have been executed by the Chunking government at a later point, thereby actualising, rather than explicating, the phrase. In this case, the use of a culturally relevant phrase to a familiar audience, rather than to an unfamiliar one with contextualised explication, situates the story on a more complex interpretive level.

\section{Chang: A Conclusion}

Unlike Rao, who is intentionally oblivious to his readers' cultural standards, Chang in this story is hyper-aware of it. Though she had gone on to translate her own works from Chinese to English, this early attempt in English of Lust, Caution exemplifies the difficulty a bilingual writer faces in conveying “a spirit of one's own in a language that isn't." When especially contrasted with Lovell's masterful translation, praised to have captured Chang's complexity, the original English version exposes the process that Chang would have engaged with, in:

decid[ing] how to handle features of the source culture (e.g. objects, customs, historical and literary allusions) that are unfamiliar to the receiving audience and modifying the source text in the process, if only through the process of explanation. (Tymoczko, 23) 


\section{SARE, Vol. 56, Issue 1 | 2019}

These decisions are equivalent to that of a translator, which places Chang, despite surface differences, in the same vicinity as Raja Rao, sorting through and picking cultural elements to be communicated through translative elements. “The Spyring," as an initial draft, complies with Tymoczko's assertion that simplification of cultural fields occurs in the choices of the postcolonial author (23), corresponding with the necessity of audience consideration in the creative process, as "the greater the distance between an author's source culture and the receiving culture of the author's work, the greater will be the impetus to simplify" (24). The vast differences in "The Spyring" and Lust, Caution testify to this pressure on the postcolonial author to simplify, given the cultural gulf between the two audiences.

\section{Conclusion}

Both Raja Rao and Eileen Chang, despite their differences of origins and literary styles, possess in common an ongoing duality in their creative processes. Edwin Thumboo terms this as a kind of "grammar" of artistic "interests" and "motives" which link the bilingual authors' lives with their art:

The writer's dilemma is whether to maintain a consistency or to run the risk of apparent contradictions. Faint hearts do not found literatures or new varieties of languages. Such grammar formation is not new to English. American, Australian, and New Zealand literature share a great deal with English literature and with each other; they are linked by deep-rooted religions and by philosophical, scientific, intellectual, and other traditions. The new literatures are seldom, if ever, linked to the same extent...the writer is formed by two worlds, at times belonging to richly complicated multiliterary ecosystems. He has twin perspectives, one established by English, the language of his creativity, the other by his mother tongue and its associated literature or literatures. (8)

As such, Raja Rao and Eileen Chang's respective styles - one braiding in the mother tongue into the English text, and the other expanding the text to accommodate mother tongue aspects - arise from the same twin perspectives and complex ecosystems. Such complexity gives rise to the formation of an idiolect, through the use of techniques such as semantic extensions, calques and explications, which place these bilingual, bicultural authors alongside translators. Thumboo asserts that such formations - something "not always conscious" but requires, in addition to general processes of creativity, an extra process of forming "links between custom, behaviour, the cosmos, and language as posited by the mother tongue" and "creativity's demands in a polydialectal 


\section{SARE, Vol. 56, Issue $1 \mid 2019$}

situation" (12) - is comparative to that of Ovid's methods of translation in Epistles, that of the metaphrase, paraphrase and imitation.

In essence, then, it would seem inevitable that a product of postcolonial work, regardless of cultural specificity, would contain sufficient permutations in its English to possess the "different lexical texture from unmarked prose" (Tymoczko 25) that is characteristic of a translated work. Therefore, as with the status of translations, such works are "an attempted revitalization of the original in another verbal order and temporal space" (Devy 186), in that both facilitate "linguistic and cultural exchange" (Apter 85) by resisting acceptable literary standards.

\section{Works Cited}

Anand, M.R. 1979, "Pigeon Indian: some notes on Indian English writing" in M.K. Naik (ed), Aspects of Indian Writing in English: Essays in Honour of Professor K.R. Srinivasa Iyengar, Chennai: Macmillan

Baral, Kailash C. 2009, "Translating the Oral: Translatability and Cultural Dynamics”, Indian Folklore Research Journal, No 9 https://indianfolklore.org/journals/index.php/IFRJ/article/viewArticle/792 (Accessed 23 Dec 2011 )

Benjamin, Walter. 2000. "The Task of the Translator", Trans. Harry Zohn, The Translation Studies Reader, ed Lawrence Venuti. London: Routledge

Chang, Eileen, "The Spyring", ESWN Culture Blog, http://www.zonaeuropa.com/culture/c20081005_1.htm (Accessed 31 December 2011)

Dharwadker, Vinay. 1999. “A.K. Ramanujan's theory and practice of translation”, Post-colonial Translation:

Theory and Practice, eds Susan Bassnett, Harish Trivedi, London: Routledge.

Devy, Ganesh. 1999. "Translation and literary history: an Indian view", Post-colonial Translation: Theory and Practice, eds Susan Bassnett, Harish Trivedi, London: Routledge.

Eagleton, Terry. 2008. Literary Theory: An Introduction, United Kingdom : Blackwell Publishing.

Kachru, Braj. 1966. “Indian English: A study in contextualization”, In memory of J.R. Firth, eds C.E. Bazell, J.C. Catford, M.A.K. Halliday, R.H. Robins. London: Longman.

Kachru, Braj. 1977. "The New Englishes and old models”, English Language Forum July 15(3), 29-35.

Kachru, Braj. 1983. The Indianization of English: the English language in India, New Delhi: Oxford University Press.

Kachru, Braj. 2005. Asian Englishes: Beyond the Canon, Hong Kong University Press. 


\section{SARE, Vol. 56, Issue $1 \mid 2019$}

Li, Jessica Tsui Yan. 2010. "Self-translation/rewriting: the female body in Eileen Chang's 'Jinsuo ji', the Rouge of the North, Yuannu and 'The Golden Cangue", Neohelicon 37:2, pp 391-403, https://www.stanford.edu/dept/DLCL/cgi-bin/web/files/Eileen_Change_and_Selftranslation.pdf(Accessed 2 January 2012)

Li, Jessica Tsui Yan. 2006. "Politics of Self-Translation: Eileen Chang”, Perspectives, 14:2, 99-106.

Mesthrie, Rajend. 2006. English in Language Shift:The History, Structure and Sociolinguistics of South African Indian English. New York: Cambridge University Press.

Naik, M.K., 1972. "Raja Rao", Twayne's World Authors Series, Vo 234. India: Twayne Publishers

Parthasarathy, R. 2006. "Editing Raja Rao", The Hindu, July 30, http://www.hindu.com/mag/2006/07/30/stories/2006073000170400.htm(Accessed 2 January 2012)

Prasad, G.J.V., 1999. "Writing Translation: The Strange case of the Indian English novel”, Post-colonial Translation: Theory and Practice, eds Susan Bassnett, Harish Trivedi, London: Routledge.

Ramanujan, A.K. 2004. "On Folk Mythologies and Folk Puranas", Collected Essays of A.K. Ramanujan, eds. A.K. Ramanujan, Vinay Dharwadker, Stuart H. Blackburn, London: Oxford University Press. 513-531, Print.

Rao, Raja. 1974. Kanthapura, $2^{\text {nd }}$ ed. New Delhi: Oxford University Press.

Thumboo, Edwin, 2006. "Literary Creativity in World Englishes", eds. Braj Kachru,

Tymoczko, Maria, 1999. "Post-colonial writing and literary translation", Post-colonial Translation: Theory and Practice, eds Susan Bassnett, Harish Trivedi, London: Routledge.

Zhang, A., Ling. Wang Hui., 2008. Lust Caution: The Story, The Screenplay, and the Making of the Film, New York: Knopf Doubleday

\section{Bibliography}

Downey, Ken. 2011. "Shaping Nativization? Indian English and Raja Rao's Kanthapura", The English Languages: History, Diaspora, Culture, Vol 2, http://jps.library.utoronto.ca/index.php/elhdc/article/view/15638 (Accessed 30 December 2011)

Gu, Ming Dong. 2006. "Theory of Fiction: A Non-Western Narrative Tradition”, Narrative, 14(3), October 2006, $311-338$

Mukherjee, Meenakshi. 1974. The Twice Born Fiction, themes and techniques of the Indian Novel in English, Arnold Heinemann Publishers. 


\section{SARE, Vol. 56, Issue $1 \mid 2019$}

Neubauer, John. 2005. “Is Western Narrative Theory Universally Applicable?" Amsterdam International Electronic Journal for Cultural Narratology, Vol 2, August, http://cf.hum.uva.nl/narratology/a05_neubauer.html (Accessed 5th January 2012)

Shen, Dan, and Zhou, Xiaoyi, 2006. "Western Literary Theories in China: Reception, Influence and Resistance”, Comparative Critical Studies, 3(1-2), 139-155.

Yamuna Kachru, Cecil L. Nelson, The Handbook of World Englishes, Wiley-Blackwell. 